This is the author's Post-print version (final draft post-refereeing as accepted for publication by the journal). The definitive, peer-reviewed and edited version of this article is published as: Kleinhans R. \& van Ham M. (2017) The Support Paradox in Community Enterprise Experiments in the Netherlands. International Journal of Entrepreneurship and Small Business 31(4), 570-589. DOI: http://dx.doi.org/10.1504/IJESB.2017.10004123

\title{
The Support Paradox in Community Enterprise Experiments in the Netherlands
}

\author{
Reinout Kleinhans $^{1 *}$ and Maarten van Ham ${ }^{1,2}$ \\ ${ }^{1}$ Department OTB - Research for the Built Environment, Faculty of Architecture and the Built \\ Environment, Delft University of Technology, Julianalaan 134, 2628 BL Delft, The Netherlands \\ 2 Department of Geography \& Sustainable Development, School of Geography and \\ Geosciences, University of St Andrews, North Street, St Andrews, KY16 9AL \\ Fife, Scotland, UK \\ * Corresponding author. Email: R.J.Kleinhans@ @udelft.nl
}

\begin{abstract}
In many European countries, community entrepreneurship is increasingly considered as a means to initiate small-scale urban regeneration in the context of austerity policies and welfare state retrenchment. However, residents in deprived neighbourhoods are often viewed to lack key entrepreneurial attributes and skills. While there is research on community entrepreneurship support, most evidence is based on cross-sectional studies and overly focussed on support provided through government policies. This paper extends the current body of knowledge by reporting a unique national experiment in the Netherlands with nascent community enterprises which received start-up support from a private foundation. The paper aims is to investigate how active citizens perceive the benefits and drawbacks of this support. The approached used is unique because of its longitudinal nature right from the start of the experiment. The paper provides an in-depth analysis of transcriptions of repeated semi-structured interviews with the same respondents (panel design) from nascent community enterprises in a number of Dutch deprived neighbourhoods. While positive feedback on the support is found, the study provides strong evidence for a 'support paradox': the support that was intended to overcome a number of entry barriers and difficulties on the road to community entrepreneurship has in fact significantly hampered progress among several of the studied community enterprises.
\end{abstract}

Keywords: community entrepreneurship, active citizenship, urban regeneration, selforganisation, The Netherlands.

\section{Acknowledgements}

This work was supported by the Ministry of the Interior and Kingdom relations [Grant Number VP 7284] and LSA (the National Association of Active Residents). Our special thanks go to Wenda Doff and Arie Romein who conducted the interviews and site visits for this project. We are also indebted to Raymond Lunes and Floor Langendijk (Ministry of the Interior) as well as Henk Cornelissen, Ties de Ruijter and Marieke Boeije (LSA) for their constructive comments during the research project and completion of the final report. We are also thankful to all $\mathrm{CE}$ representatives who happily co-operated multiple times with the interviews.

\section{Introduction}

Entrepreneurship is commonly believed to improve the economic strength and 
innovation of countries and cities, but also of neighbourhoods and local communities (Baumol et al., 2007; Shane, 2009; Mason et al., 2015). However, the relationship between community and entrepreneurship is a relatively neglected topic in the literature, partly because of the emphasis on individual entrepreneurs (Ratten and Welpe, 2011; Lyons et al., 2012 et al., 2012; Fortunato and Alter, 2015). Ronald Coase, the winner of the 1991 Nobel Prize for economy, has labelled the relation between entrepreneurship and community as the next true frontier for entrepreneurship research (Coase and Wang, 2011, cited in Lyons et al., 2012, 19).

In this context, the rise of various forms of community-based entrepreneurship across Europe is both interesting and relevant. Due to the economic crisis, many countries have been implementing austerity measures and cuts in public policy, alongside longer trends of welfare retrenchment. To compensate for austerity regimes and welfare retrenchment, governments are putting more emphasis on active citizenship. Citizens are expected to take responsibility and organise themselves to fill in gaps left by government spending cuts in health care, education, employment and neighbourhood governance (Wells, 2011; Newman and Tonkens, 2011; Bailey and Pill, 2015). Resident-organised, community-based entrepreneurial activities are increasingly seen as solutions for deficiencies in public services and neighbourhood regeneration efforts (Bailey, 2012). Community enterprises often arise "from a perception that there are serious deficiencies in a particular area which need to be addressed and where the perception is that other agencies are unlikely to provide solutions. These deficiencies may be defined in social, economic and demographic terms as degrees of deprivation, poor health, inadequate housing or a lack of community facilities. These perceptions motivate individuals and groups to combine together to set up an organisation which can begin to provide solutions" (Bailey, 2012, 26, see also Peredo and Chrisman, 2006; Somerville and McElwee, 2011).

However, a major concern is that especially those citizens most in need, in the most deprived neighbourhoods, have the least capacity to solve problems in own their communities (Kisby, 2010; Painter et al., 2011). On the one hand, stimulating entrepreneurship in deprived neighbourhoods is seen as a crucial element in strengthening economic development through the creation of jobs and increased labour productivity, as well as increasing social inclusion (Blackburn and Ram, 2006; Welter et al., 2008; Lyons, 2015). On the other hand, residents in deprived communities are often viewed to lack key entrepreneurial attributes and skills (OECD, 2003; Williams and Huggins, 2013, 168). This 'vacuum' between citizens and governments is the starting point of policies "to help citizens to help themselves" across European countries. Although the literature on community enterprises is relatively small, studies have reported on initiatives in the UK (Bailey, 2012; Williams and Huggins, 2013), Germany (Welter et al., 2008; Zimmer and Bräuer, 2014), Norway (Bjørnå and Aarsæther, 2010), Sweden (Lundqvist and Middleton, 2010; Sundin, 2011), and the USA (Varady et al., 2015).

This paper contributes to the scientific and policy discussion on supporting community entrepreneurship in (mostly) deprived neighbourhoods by providing an account of the paradoxical effects of a national community enterprise project in the Netherlands. While Dutch examples of community enterprise are not necessarily restricted to deprived neighbourhoods, it is this particular spatial and social context which generates the strongest interest in the potential of CEs to generate benefits for local communities. The aim of the paper is to get more insight in how active citizens perceive the benefits and drawbacks of support provided for their attempts to establish a 
community enterprise. A particularly interesting feature of this study is that the support for developing entrepreneurship is provided by a private foundation, while the majority of the literature on community entrepreneurship deals with government policies. Our study is unique in that it follows an experiment with nascent community enterprise startups right from the start by using a panel design with repeated semi-structured interviews with the same respondents. This research approach meets the repeated calls in the literature for more longitudinal, qualitative and inductive approaches in research related to entrepreneurship (Dana and Dana, 1995; Hopp and Stephan, 2012; Henry and Foss, 2015), which has hitherto been dominated by quantitative approaches.

The next section lays the foundation for this study by discussing the relevant literature on community-based entrepreneurship and support policies. The following section introduces the support project in more detail, followed by an explanation of our approach, data and analytical strategy. Subsequently, several sections report the main outcomes from the transcript analysis. The final section presents the conclusions.

\section{Supporting Community Entrepreneurship}

\subsection{The nature of community enterprises}

In the Introduction, we explained how active citizenship is framed as a viable alternative to state-based welfare provision which is reduced by austerity regimes and welfare retrenchment. Of particular interest in the current scientific, societal and policy context are entrepreneurial forms of active citizenship, such as social enterprises, which reflect the permeation of neoliberal values into civil society (Dart, 2004). Community Enterprises (CEs), like social enterprises (SEs), have a strong commercial ethos and generate a substantial part of their revenue through trading, relying upon 'enterprise' rather than government subsidy to finance their social objectives (Tracey et al., 2005, 335). There are also differences between CEs and SEs. First, CEs define their social purpose in relation to a defined population or sub-group living in a spatially defined area (Bailey, 2012, 4; Pierre et al., 2014, 253), whereas SEs are not by definition tied to a specific area. Second, unlike many SEs, CEs are built on strong local linkages and also have democratic structures which enable involvement of organisational members in the governance of the enterprise (Pearce, 2003; Tracey et al., 2005, 335).

Compared to the literature on SEs (Bacq and Janssen 2011), the volume of work on CEs is still relatively limited, and so is the number of definitions. Based on the work of Pearce (2003), Peredo and Chrisman (2006), Teasdale (2010), Somerville and McElwee (2011), Bailey (2012), Pierre et al. (2015) and Healey (2015), CEs are here defined as businesses which are:

- established by people living and/or working in a (spatially) defined community,

- independent, not-for-private-profit organisations, which are owned and/or managed by community members,

- locally accountable and highly committed to delivering long-term benefits to local people, by providing specific goods or services,

- seeking to generate a surplus through, at least in part, engaging in trade in the marketplace, and reinvest the surplus in the business or community,

- bearing economic risks related to their activity, and are very committed to involving local people and other partners in their activities.

The goods or services delivered by CEs may vary from a range of community facilities 
(shops, pubs, recreational or health facilities), community centres and community development to affordable housing, property management and consultancy services. CEs need to acquire funding in various forms (subsidies, loans) to start up their activities, not just the ones that contribute to their objectives, but also those that cover operational costs. Key to the functioning of CEs is that they acquire assets, i.e. buildings, land or other sources from which they can draw capital. In entrepreneurial terms, community enterprises are looking for niche markets without a potential to attract fully commercial entrepreneurs (Bailey, 2012). Many CEs arise in (former) urban regeneration target areas, where regeneration programs have come to a stop, creating both challenges and opportunities for CEs (Carpenter, 2013; Varady et al., 2015).

Despite the scientific and societal relevance of CEs, there is surprisingly little empirical research on community-based entrepreneurship in Western Europe (Bailey, 2012; Pierre et al., 2014; Fortunato and Alter, 2015). Bailey (2012) analysed five case studies in multiple localities while others focus on one specific CE case study (Teasdale, 2010; Smith, 2012; Van Meerkerk et al., 2013; Healey, 2015). The literature shows that CEs usually forge alliances with various stakeholders, including (local) governments. Over time, many CEs have transformed from 'subsidy-dependent' resident councils to community-based enterprises. In this vein, Selsky and Smith (1994) have described community entrepreneurship as a type of leadership that is appropriate for practicing social change. They assert that "community-based social change settings are highly dynamic and complex. They are characterized by diverse interests, temporary and fluid alliances, and fast-paced and equivocal events that confound traditional leadership concepts" (Selsky and Smith, 1994, 277; Ratten and Welpe, 2011). Thus, "community entrepreneurs play their most critical role in developing the collective capacities of organisations sharing interests in one or more community issues" (ibid., 278).

With reference Bourdieu (1986), Somerville and McElwee (2011, 323) argue that $\mathrm{CE}$ can be understood in terms of capital that is simultaneously economic, social and cultural, by creating wealth, developing community and transforming local culture. Social capital can enable entrepreneurship. The mutuality of shared interests encourages and engages entrepreneurs in sharing entrepreneurial expertise (McKeever et al., 2014). A "primary strength of community enterprise is that it can harness social capital in local communities and use it to achieve positive outcomes through mobilizing volunteers, board members and paid staff" (Bailey, 2012, 30). CEs never work in isolation but usually co-operate with local actors, building relationships with other organisations are crucial to CEs (Ratten and Welpe, 2011; Smith, 2012; Healey, 2015). According to Fortunato and Alter $(2015,450)$, "the field of entrepreneurship continues to witness a deep transition from thinking about entrepreneurship as an individualistic effort, supported by community actors - toward one that sees entrepreneurship as a socially embedded, community-wide effort where many actors can contribute".

\subsection{Supporting community entrepreneurship in deprived neighbourhoods}

Many European countries have witnessed decades of urban regeneration policies, which have not been altogether successful in economic terms. In an attempt to boost the economic regeneration of deprived urban areas, policy makers turned to approaches for fostering entrepreneurship specifically at local levels (OECD 2003). Harnessing entrepreneurship in such areas is considered a key element in enhancing economic development through job creation and increased productivity, as well as ensuring heightened social inclusion (Williams and Huggins, 2013, 166; see also Blackburn and Ram, 2006; Lyons, 2015). The nature of support policies for deprived areas varies, 
depending on the national and local context and governance structures.

However, such support approaches have been criticised for various reasons. The first reason is a risk of overestimating the positive impacts of start-ups in deprived neighbourhoods once they have received support to establish themselves. According to Shane $(2009,141)$, "policy makers believe a dangerous myth" in thinking that start-ups are "a magic bullet" that will transform depressed areas and "conduct all sorts of other economic wizardry". Blackburn and Ram $(2006,85)$ claim that "the policy 'fad' of uncritically advocating that entrepreneurship is a key route for improving individual and societal economic development" should be avoided.

A second and related reason for critique concerns the question whether you can "make" entrepreneurs. Within deprived communities, residents are often viewed to be lacking in key entrepreneurial attributes and skills (OECD, 2003; Welter et al., 2008; Williams and Huggins, 2013). This is part of a larger concern that especially those citizens most in need, in the most deprived neighbourhoods, have the least capacity to solve problems in own their communities, and therefore still need support. However, "policy interventions in deprived urban neighbourhoods need to consider that providing incentives to individuals who do not necessarily have the skills, knowledge or capacity to succeed as an entrepreneur may result in low-quality entrepreneurship being fostered" (Williams and Williams, 2012, 666; see also Greene et al., 2007; Welter et al., 2008). According to Shane $(2009,143)$, "not the best entrepreneurs" are the most likely to respond to policy incentives. Compared to people with paid jobs, unemployed people will be more likely to respond because they "have less to lose by becoming entrepreneurs". Additionally, "unsubsidized and/or unsupported traders may be pushed out, resulting in little or no impact on the local economy" (Williams and Huggins, 2013, 175). For this reason, Shane asserts that "policy makers need to "stop spreading the peanut butter so thin' [...] and concentrate time and money on extraordinary entrepreneurs, and worry less about the typical ones" (ibid., 146).

A third reason is a lack of understanding regarding the role of community in shaping entrepreneurship and providing for entrepreneurs' needs, and therefore lack of proper community-oriented support strategies. Much of the literature focuses on what makes individual firms successful, rather than what makes communities successful (Fortunato and Alter, 2015). Dana and Dana (2005) reviewed research that places entrepreneurship in the context of its environment, showing that entrepreneurship is culture-bound and that policy on entrepreneurship should therefore be culture-specific. Because communities consist of social networks, shared identities, norms, values and common practices, they have their own local cultures. Cultures of entrepreneurship vary across population groups and spatial areas (Williams, 2007; Hopp and Stephan, 2012). Hence, "if economic and community development policies use traditional business strategies to support entrepreneurs and entrepreneurial development while ignoring culture, that strategy will likely fail or at best achieve sub-optimal performance" (Fortunato and Alter, 2015, 448). Others have found limited use of formal enterprise support services, which may be the result of negative perceptions regarding whom it is for, availability and bureaucracy (Williams and Huggins, 2013, 175). Ultimately, the result of well-intended support may be a condition of disentrepreneurship. Disentrepreneurship refers to a situation in which "a community creates, either systematically or by accident, an environment unsuitable for establishment or sustainability of existing entrepreneurial activities. It may do this through public policy initiatives that penalize or prohibit entrepreneurial activities, by promoting cultural values and norms that discourage entrepreneurship, or by failing to create the required 
legal, institutional and structural environment necessary for entrepreneurship to become established" (Honig and Dana, 2008, 11).

A fourth reason for criticising support policies for (community) entrepreneurship is a simplistic perspective on motivations of entrepreneurs. As mentioned earlier, the communis opinio among policymakers is that entrepreneurship may provide avenues out of economic adversity and poverty, implying that entrepreneurship is born straight out of necessity. However, "situations of adversity can provide opportunities for individuals to respond in an entrepreneurial fashion, for example by starting a business to cater for local needs" (Blackburn and Ram, 2006, 77, see also Peredo and Chrisman, 2006; Bailey, 2012). Already in 1995, Dana distinguished three general types of (potential) entrepreneurs. A first type may be 'opportunity seekers', who are driven by cultural values such as thrift and frugality, while others have psychological characteristics such as a high sense of achievement or aim for social changes in 'the community'. A second type includes residents who lost their regular job and subsequently venture into entrepreneurial activities to increase their income and social status and decrease their 'marginality in society'. A third type are entrepreneurs who identify a market opportunity, either by 'stumbling across' it or by alertness (Dana, 1995, 60). In their study of entrepreneurs' motivations in deprived neighbourhoods, Williams and Williams $(2012$, 674) found that "the motivations could not be solely classified as 'necessity' or 'opportunity' based. Rather, necessity and opportunity were both copresent, and motivations were influenced by the locality of the entrepreneurs". They conclude that a dichotomy of understanding entrepreneurial motivations in terms of either necessity or opportunity is misleading and simplistic.

In sum, the literature has revealed a number of shortcomings of community entrepreneurship support, which are partly the result of a lack of understanding of the complex relation between entrepreneurship and 'community'.

\section{A Support Project for Dutch Community Enterprises}

In this section we will introduce the community enterprise support project that was the focus of our panel study on nascent community enterprises in the Netherlands. The project was initiated and led by the non-profit organisation LSA; the National Association of Active Residents (Landelijk Samenwerkingsverband Actieve Bewoners). The LSA is a platform of approximately 70 residents from different associations spread over the Netherlands. It is a small private non-governmental organisation, consisting of a general director, project managers and support staff, which receives a large part of its funding through the Dutch Ministry of the Interior. Since its inception, LSA has looked for ways to strengthen the voice of residents in neighbourhood (regeneration) policies and to stimulate bottom-up initiatives of single residents or groups to improve the quality of life in their communities (see http://www.lsabewoners.nl/en/).

Inspired by British community enterprises and the role of Locality (a sister organisation of LSA in the UK) in supporting such initiatives, the LSA took the initiative to start experimenting with community-based entrepreneurship in the Netherlands. LSA gained political and financial support from the Dutch government, $€$ 2 million from the Dutch Lottery Fund (Nationale Postcode Loterij) and money from the Fund Working on Housing (Fonds Werken aan Wonen) (LSA, 2011, 2015). In July 2012, the Project Community Enterprises (Project Bewonersbedrijven) officially kicked off with a number of residents groups which expressed a willingness to work towards 
fitting the principles below. The basic idea behind the experiment was to explore whether and how the British concept of CEs can be transferred to the Dutch context while being aware of the difficulties of transferring practices between the highly different British and Dutch contexts. To guide the experiment, the LSA (2011) has formulated four principles around which Dutch CEs should revolve:

1. CEs work on economic, physical and social development of an area which is recognised by residents as a meaningful unit (i.e. a community).

2. CEs are independent, self-sufficient and profits flow back into the own neighbourhood and will not accrue to private persons.

3. CEs are initiated by residents, owned by residents and managed by residents.

4. CEs are focussed on collaboration with resident associations, local governments, other institutions and (local) business.

A key characteristic of the LSA support project was that nascent CEs could apply for a starting grant (seed money) of a maximum of $€ 200,000$ if they submitted a business plan which was subsequently approved by an external evaluation committee with representatives from business, private enterprise and community development work.

Besides the potential of receiving a starting grant, LSA also offered other types of support in setting up a CE. This support ranged from information meetings and fact sheets, to individual counselling and information brokering on site by LSA counsellors. Fact sheets included, for example, legal information related to establishing a foundation, the legal form for CEs preferred by LSA. To enable knowledge exchange beyond the initiatives themselves, thematic readers were compiled, dealing with issues of writing a business plan, entrepreneurship, collaboration, finance, accounting, management, and public procurement, as well as check lists for creating a vision, internal policies (e.g. on volunteers) and liability.

Counselling has played a key role in the support efforts of LSA, especially in the planning and starting phase of nascent CEs. LSA started out with a full-time counsellor and a supporting secretary, but shortly after the start of the project this capacity was already insufficient, because the amount of support needed by the start-ups was higher than expected. The main counsellor was replaced by three regionally based external counsellors and one central project manager. Approximately one-and-a-half year in the project, this combination was again replaced by a main counsellor, a project manager for supporting the development of business models and a secretary. In addition, the director of LSA also provided counselling to CEs. Acknowledging the limited staff capacity, the aim of LSA subsequently shifted from providing support to arranging tailored local external support for CEs. As such, the networking function of the LSA has become increasingly important over time, at the expense of providing support by her own staff members (Kleinhans et al., 2015).

An important element of the Dutch CEs that joined the experiment is their organisational structure. Based on British experiences with managing CEs, LSA has developed a basic organisational model for CEs participating in the support project. The model implies that a CE has a resident board which is responsible for the CE's vision and direction, and is responsible and liable for its activities. While the majority of board members should be residents from the target community, external experts can also be recruited. The board employs a main entrepreneur, who can be paid from the starting grant, and who is in charge of management and developing entrepreneurship and activities to generate income. In the context of the aforementioned four principles, this 
structure is supposed to guarantee CE ownership by residents.

A final element of the support project is that LSA has consistently labelled it as a learning process, implying that there is usually no unidirectional flow of coaching and information from LSA to CEs, but that there is continuing development of knowledge and concepts while tackling all problems encountered during the project (LSA, 2015).

It is important to add a critical note here on the process as described above. Seen from the outside, the process is very top down and regulated, while the underlying objective is to stimulate active citizens in taking matters in their own hands and 'free' them from 'policy reigns', something of which LSA has claimed that it never occurred during the periods of state-led and state supported urban renewal since the 1970s (LSA, 2011). Hence, the paper will investigate how active citizens attempting to establish a community enterprise, perceive the benefits and drawbacks of the LSA support.

\section{Approach and Methods}

The data used in this study was collected by a team of university-based researchers led by the authors of this paper, and funded by the Ministry of the Interior and the LSA. The funders took part in the advisory board of the research project, but the researchers were independent and responsible for reporting the outcomes of the study. The researchers conducted a panel study of 16 different CE start-ups across the Netherlands and followed them for almost three years (July 2012-February 2015). The study group of initiatives is not a random sample, but consists of self-selected groups of residents which matched the LSA principles for the experiment. We make no claims about similar initiatives outside the experiment, or the representativeness of the case studies for other initiatives.

Considering that we are dealing with a relatively new, highly context-embedded phenomenon in the Netherlands and an exploratory search lead by a 'how' question (see Yin, 2012), we have chosen to adopt a case study approach. There are too many variables at stake to apply a more (quantitative) research design. Henry and Foss (2015, 403) have argued that the case method has not been used frequently in entrepreneurship research to date because it is not yet fully accepted as a legitimate research approach. They have demonstrated the merits and added value of the case study approach, dismissing criticisms in relation to reliability, generalizability and theory building capacity as "both disproportionate and out-dated" (ibid.). According to Dana and Dana (2005), inductive designs of qualitative research are more appropriate for new theories and understanding (community) entrepreneurs' dynamic interactions with their environment than hypothetico-deductive (quantitative) methodologies.

Of the 16 nascent CEs which we followed, 10 are relevant for the purpose of this paper, because they went through all stages of the LSA support, including the submission of a business plan for a starting grant. The study was divided in two phases. In phase 1, we included all case studies and monitored their progress in their preparatory efforts. At the end of phase 2, we made a selection of initiatives that had made significant progress towards starting a CE. In Phase 2, we further focused our research on this selection of nascent CEs. During this phase, two new cases were added to the selection because of their quick progress. 
Table 1 A brief overview of the case studies

\begin{tabular}{|c|c|c|c|}
\hline City & Name of the CE & $\begin{array}{l}\text { Assets and main component of } \\
\text { the business model }\end{array}$ & $\begin{array}{l}\text { Interviewed } \\
\text { stakeholders }(n=21)\end{array}$ \\
\hline Amersfoort & Kruiskamp Onderneemt! & $\begin{array}{l}\text { Renting out office/work spaces, } \\
\text { recreation facilities }\end{array}$ & $\begin{array}{l}\text { Two initiators and } \\
\text { one board member }\end{array}$ \\
\hline Arnhem & Bewonersbedrijf Malburgen & $\begin{array}{l}\text { Renting out rooms and office } \\
\text { spaces, cheap restaurant }\end{array}$ & $\begin{array}{l}\text { Board chair and the } \\
\text { main entrepreneur }\end{array}$ \\
\hline Emmen & $\begin{array}{l}\text { BewonersBedrijf Op Eigen } \\
\text { Houtje }\end{array}$ & $\begin{array}{l}\text { Renting out office/work spaces, } \\
\text { food and health, recreation } \\
\text { facilities }\end{array}$ & $\begin{array}{l}\text { Two initiators and } \\
\text { the main entrepre- } \\
\text { neur }\end{array}$ \\
\hline Haarlem & 't Badhuis & $\begin{array}{l}\text { Renting out recreation spaces } \\
\text { and reception rooms }\end{array}$ & Three initiators \\
\hline Hengelo & Bewonersbedrijf Berflo Es & $\begin{array}{l}\text { Services, facilities, maintenance } \\
\text { of public space }\end{array}$ & $\begin{array}{l}\text { One board member } \\
\text { and the main } \\
\text { entrepreneur }\end{array}$ \\
\hline Hengelo** & Bewonersbedrijf 't Geerdink & Services, facilities & $\begin{array}{l}\text { Chair of the CE } \\
\text { board }\end{array}$ \\
\hline Leeuwarden & $\begin{array}{l}\text { BewonersBedrijf Heechterp- } \\
\text { Schieringen (BBHS) }\end{array}$ & $\begin{array}{l}\text { Service provision, maintenance } \\
\text { of public spaces }\end{array}$ & $\begin{array}{l}\text { One board member } \\
\text { and the main } \\
\text { entrepreneur }\end{array}$ \\
\hline Sittard & Not yet established & - & Two initiators \\
\hline Venray & Not yet established & - & Two initiators \\
\hline Zaanstad** & $\begin{array}{l}\text { BewonersBedrijven } \\
\text { Zaanstad }\end{array}$ & $\begin{array}{l}\text { Renting out office spaces, } \\
\text { providing care, renovation } \\
\text { works }\end{array}$ & Initiator \\
\hline
\end{tabular}

** These cases were added in the second stage of the research and have been studied in two rounds instead of four.

Using a panel design, we have conducted repeated interviews (2-4 times in three years), observations and document analysis. The interviews were targeted at the initiators of CEs, board members, the main entrepreneurs in the CEs, and professionals from local governments and housing associations who were closely involved in the initiatives. In most of the cases in Table 1, we have visited the research sites multiple times, which is one of the strategies offered by Guba and Lincoln (1982) to overcome problems related to credibility, transferability, dependability and confirmability of case study research.

Interviews were conducted at the premises of the respondents, based on a semistructured interview guide that included a range of open-ended questions regarding the aims of nascent CEs, the development of their business plan and activities, their staff composition (paid staff and volunteers), and their opinions on the support provided by the LSA. Interviews lasted between 45 minutes to 2 hours and were recorded and subsequently transcribed verbatim for content analysis. We then conducted a thematic analysis of the transcripts, based on the inductive approach suggested by Miles and Huberman (1994). Their contribution to qualitative research methodology is renowned for its focus on the analysis of case data. They argue that an inductive, iterative approach should be adopted, in which documentary evidence, interview transcripts, supporting notes and other materials need to be read and re-read several times to allow key issues and themes to emerge and be coded. We identified five overarching but related themes of interest in the research context: (1) support and seed money as a sine qua non, (2) inadequate support and changing preconditions (3), strict guidance and little room for experimentation, (4) contradictions between project principles and practice, and (5), the need for professionalization of all involved actors. Our analysis of interview transcripts does not imply any claim of 'authenticity' of 'verificational realism' (Crang, 2002), but is able to unearth common and different experiences among 
the interview respondents.

Subsequently, we coded text in the interview transcripts which corresponded to these themes and labels in more detail. Third, we analysed connections between the emergent themes. In order to safeguard their anonymity, respondents are denoted by their role in the respective CE only, leaving out references to locations (see Table 1). Counsellors of LSA who have been mentioned by name during the interviews are denoted with a fictitious name. Below, the paper turns to the results of the interviews, which will provide detailed insights in how active citizens perceive the benefits and drawbacks of support provided.

\section{Results of the Interviews}

\subsection{Support and seed money as a sine qua non}

As mentioned in section 3, LSA has deployed a range of efforts to support resident groups in the process of starting up their own CE. A key element has been the one-toone counselling provided by LSA staff to individual CE members. All interviewed respondents acknowledged the fundamental role of both the seed money and setting the right steps towards acquiring this, through counselling:

"Counselling of LSA? That was absolutely necessary. We initially got stuck in ideas. You have several ideas as a community enterprise, you want to do something, but you don't know what the next step should be. And then it was great that Fiona from LSA came along. She said, "well guys, get a sieve and filter your ideas, and start with the basis." (CE board member)

While one of the four key principles of CEs in the support project is that they should be independent and self-sufficient, this does not apply to the process of starting up the business. Some respondents claimed that the seed money is a necessary precondition:

Interviewer: "To what extent do you feel that LSA is a condition here?

Respondent: Yes, it forces you to act. You need the seed money to start the enterprise. And the precondition for the money is a decent business plan. So yes, no plan, no money and everything." (CE initiators)

The fact that the business plan was an indispensable element part of the process of acquiring the seed money from LSA has resulted in a number of problems in the cooperation between LSA and residents groups that were trying to establish their CE. This is an issue that we will analyse in full detail.

\subsection{Inadequate support and unclear and changing preconditions}

Apart from varying starting up issues, almost all respondents have struggled (or are still struggling) with the business plan. In the process towards submitting the business plan to the external evaluation committee, resident groups have asked for and implemented the advice of LSA counsellors who were not part of this committee (see section 3). In some cases, respondents feel that they have received incorrect advice regarding the structure and content of the business plan, and attribute the rejection by the evaluation committee to this matter: 
"Yes, we were summoned to the external evaluation committee to present our business plan. Our plan has been declared unfit on several points and thus we did not get the seed money. We are working very hard to improve this [...]. The committee, they missed the soul of the story. And that's correct... Based on advice from LSA, we removed several sections from the plan to improve readability. But if I look closely to the comments of the evaluation committee, we exactly removed those points that they missed in the story, but were present in the original version of the plan." (CE initiators)

This experience has not been unique. Several respondents have observed that the criteria for the business plans were not clear in advance and gradually unfolded during the support project and the process of all CEs writing business plans. This has resulted in inconsistent advice, confusion and many required revisions:

"Well, LSA has not always been clear in her expectations, for example on how they wanted to see the business plan and its components. So you need to work that out completely for yourself. And the moment that you submit it, adding ' this is how we feel it should look like', then 'wait a minute...' Interviewer: They say it should look different?

Respondent: Yes, it should look like this and this and then you can go home and start revising it again." (CE board member).

Some interviews reflected on the lack of requirements at the outset, explaining that they had expected a consensus between the evaluation committee and LSA staff members, so that criteria could have been agreed upon. But they stumbled across a non-existent consensus, which is clearly worded by one of the respondents:

"And then the LSA sent Janet, who took over from Fiona ... We asked her how the business plan should look like and which criteria were applied by the external evaluation committee. But she neither knew that!! She said, 'let's set the bar very high'. Well, that's very strange, you have been part of an experiment for more than a year and you say that we are not doing it right, there are few directions, so why can't this evaluation committee visit us, advise, practice with us, whatever!" (CE board member)

On several occasions, moving back and forth of the draft business plan has created a lot of frustration among CE members:

Interviewer: "Are you being informed of the criteria for the business plan?

Respondent: Yes, they tell you what they still miss in it. And then we revise it and send it in, they send it back and ask for revisions again. I think we have revised it roughly 45 times! And then we said 'let's quite this nonsense. We are going to write our own business plan, how we see it here, and that's what we are going to do'." (Chair of the CE board)

\subsection{Strict guidance and little room for experimentation}

As explained before, LSA has envisioned that CEs in their project should revolve around four main principles that affect CEs' nature and functioning. This has resulted in 
much criticism from nascent CEs regarding a top-down 'ideal mode' of community entrepreneurship that does not adequately take into account specific local conditions and opportunities. The general sense among many respondents is that the principles do not function as a starting point for experimentation, but as a mould in which all local initiatives should fit, as is eloquently explained by one of the respondents:

"The process is a straitjacket, it's not completely fair. They [LSA] offer a pot of money as bait, which is quite a lot.

Interviewer: Do you mean the seed money?

Respondent: Yes, but you need to comply to their rules. But as I feel it, initiatives that arise in communities are always a bit anarchistic, a bit off the beaten track. And it now feels as if they [LSA] say, 'Oh my goodness, something is happening of the track, let's encapsulate it quickly and then it will go with the flow again'." (CE board member)

Several respondents have reflected upon the label 'experimental' in the LSA project, which does not seem to resound with the actual practice of support, and explained how this has eroded their inspiration and motivation:

"The LSA got a big pot with money to do pilots. Pilots imply openness for experimentation, that things can go wrong. It means that you should not prescribe everything beforehand, but just let it work and see whether or not it flourishes. The process now increasingly looks like a trap [...].To what expense? How long can we deal with this until it wipes out our spontaneity?" (CE initiator)

Some respondents have connected the changes in LSA staff during the project with a strict adherence to a theoretical framework in order to sustain the support, but with the downside of prescribing the nature of local CEs, their aims and constituency:

"Yes, we have seen different faces [in LSA] pass along, people with specific expertise who were expected to advise community enterprises, but this has not always run smoothly. We have repeatedly felt annoyed that we were lead on certain tracks, to put it this way, 'are we actually doing the right thing, does it connect to our neighbourhood?' Are we being prescribed too much, as in 'you should do it this way', based on a theoretical thinking about how to establish a community enterprise." (CE board member)

The latter quote touches upon another main theme in the research, which seems to reveal several contractions between the overarching principles of starting CEs in the support project (see section 3) and the unfolding practices of achieving this, both among LSA staff members and individual residents in starting CEs.

\subsection{Practice contradicts principles}

While the respondents generally agree with the four overarching principles of CEs as formulated by the LSA, some of them feel that their meaning was taken too literally in terms of the provided counselling. This observation especially applies to the second principle (CEs are independent) and the third principle (CEs are initiated by residents, owned by residents and managed by residents). Several respondents question these very 
principles, by claiming that residents (especially from deprived neighbourhoods) lack the knowledge and skills to establish and subsequently manage a $\mathrm{CE}$, and therefore need intensive support and cannot be independent, at least in the starting up phase:

"What happened is that they [LSA] have thought, 'Well, let them just mess around a bit, the business plan should come from themselves, we are not providing a pattern for it. But that is outright nonsense.

Interviewer: Why is that?

Respondent: People who write a business plan do have expert knowledge, you know, otherwise you will not start up a business. Residents lack that knowledge, they need help." (CE initiators)

Others use the same principles to point out that LSA should exert more trust in the efforts, experimentation and outcomes of nascent CEs instead of trying to mould them all to a single model of community-based entrepreneurship:

"Look, apparently it is difficult to digest, but this is a pilot, an experiment, and an experiment is allowed to fail. Of course you want to set out clear starting points. But if you look at the people who took the initiative, you just know and trust that they will succeed. Please do not make problems, LSA should keep that in mind and stop acting so bureaucratic!

Interviewer: Is that what they are doing?

Respondent: It is precisely what they blame local authorities and housing associations for, but they take a very firm line themselves." (Entrepreneur)

One of the interviewees addresses the tension between bottom-up social innovation and the shared perception that LSA has not been very open to new ideas and concepts within the broader idea of community-based entrepreneurship. This particular CE is the only one in our study which specifically and deliberately added social care to their aims and core-business, in a relatively new institutional setting of 'social neighbourhood teams'. Within the local social neighbourhood team, this CE has taken a role as subcontractor, but not to the liking of one of the LSA staff members:

"This was a big discussion. Joining a social neighbourhood team, he [LSA staff member] thought it did not it into the concept of community enterprise. But we argued, 'John, listen, this is quite innovative. Please think along with us, we feel that this is the future'. But no, it seems as if LSA has become exactly the type of old-fashioned institutions they are fighting against.... So if you want that neighbourhood residents develop these kind of new things, then you should be open to innovation." (CE initiator)

This brings us to the question whether not only residents, but also LSA staff members are perceived to have sufficient expertise to support the establishment of CEs.

\subsection{The need for professionalization on both sides}

From the perspective of CE initiators, board members and entrepreneurs, we described a perceived lack of expertise in relation to the business plans, not only among active residents but also among LSA counsellors. Many respondents have acknowledged that the support project, which started in 2012 and continues to date, not only implies a full 
learning process for nascent CEs but also a learning curve for the main supporting organisation. Again, we find evidence of a contradiction between the guiding principles and practice in the first three years of the support project. Even if nascent CEs are supposed to develop themselves, all eyes are turned to LSA to provide answers to the 'wicked questions', as is exemplified by the following quote:

"Well, you know, of course this is a fantastic project. Especially the option to acquire seed money, to really start something... On the other hand, you can see that LSA has a steep learning pathway ahead. How impractical some of the support is. How they dealt with the business plans. But just as we have to learn, LSA has to learn. And we can suffer occasionally from that. How long do you make people wait for the right answer?" (CE initiators)

While many respondents agree on the need of 'professional' advice form LSA, there are different opinions on the extent to which LSA staff members should have sufficiently 'professionalized' at the start of the project', as the project remains a learning pathway for them as well. Some respondents suggest that LSA should have a head start on the issues that were bound to arise in the genesis of local CEs:

"We find that LSA is searching its way to a kind of format for community enterprises. That's not bad, but it sometimes puts the brake on making progress. Then you are busy, writing down an idea and when you submit it or ask a question next time, you get quite different feedback [...]. On the other hand, it would be nice if they were more knowledgeable than us on that point, so that they really could offer tailored advice. For example, if I ask a question about insurance, they should know the answer because they know that the question will rise." (Entrepreneur)

Others are more critical and claim that LSA should basically have the expertise to clear the common problems of starting CEs, based on their [LSA's] long involvement in the theme of bottom-up initiatives and community development:

"I do not understand where they [LSA] derive their right to exist from. They have grappled with the theme for more than 20 years, but they have not been able to start the desired number of experiments and provide proper professional support to these experiments. This has lacked from the very beginning. Questions regarding legal status and regulations, tax issues, how to deal with allowances for volunteers, all of these could have been sorted out in advance." (Entrepreneur)

Regardless of these differences in opinion, the bottom line of the responses is that professionals were needed to provide tailored support and to pave to way to getting the business plan funded and the CE established, but not professionals patronizing active citizens. Ironically, the need for professionals is exactly the line of thinking from which LSA tried to distinguish itself from the beginning of the project, essentially by claiming that residents (who are not by definition professionals) should be able to establish CEs within a relatively limited amount of time. 


\section{Conclusions}

Across Europe, community entrepreneurship is increasingly being considered as a key component of bottom-up urban regeneration, especially in deprived neighbourhoods. However, residents in such areas are often assumed to lack entrepreneurial competences and skills. A plethora of policies has been enacted to support community entrepreneurs, alongside the advocacy of local entrepreneurship as being inherently good (Williams and Huggins, 2013, 176). Using a panel study with in-depth interviews, this paper has revealed how nascent Dutch community enterprises perceive the merits, limitations and unintended outcomes of support from LSA, a national resident platform that set up a project to experiment with the British concept of community enterprise.

Our findings provide strong evidence for a 'support paradox'; the support that was originally intended to overcome various entry barriers and difficulties on the road to bottom-up community entrepreneurship has in fact raised many obstacles to progress for many nascent CEs in the context of the LSA experiment. The main conclusion is that 'making' active citizenship in the form of community-based enterprise is extremely difficult, because these notions imply inherently bottom-up processes which are difficult to steer from above without creating resistance and frustration.

The first and most fundamental paradox appeared in terms of the perceived opportunity to experiment with community enterprise. The term 'experiment', which was the starting point of the support project, suggests an approach with trial, error, and diversity in local solutions. While the literature on community enterprise posits that the local context and contingencies are crucial to the genesis, aims and functioning of CEs (Peredo and Chrisman, 2006; Somerville and McElwee, 2011; Bailey, 2012), our results shows substantial friction between the 'muddling through' efforts of CEs and their perception of a strict top-down support approach from the LSA. This approach has tried to mould residents' initiatives into a single model of community-based entrepreneurship that tightly fits all criteria set by the LSA, defines the outcomes in advance and does not properly take into account the couleur locale. The resulting resistance from residents is hardly surprising from the perspective of earlier studies showing that ignoring local (entrepreneurial) cultures will likely result in sub-optimal or failing support (Dana and Dana, 2005; Williams, 2007; Hopp and Stephan, 2012; Fortunato and Alter, 2015).

A second paradox concerns the framing of the experiment. LSA has positioned its support project in a discourse that emphasizes the inadequacy of local institutions (in particular local authorities and housing associations) to stimulate bottom-up initiatives, by claiming that these institutions hitherto have been too strict and bureaucratic in their dealings with active residents, thus only allowing for 'traditional' policy participation within a top down set of rules and regulations (LSA, 2011). Ironically, however, is the recurring observation from active residents that the way in which support was provided (or withheld) actually puts LSA in the same league of 'old-fashioned' institutions that it has so fiercely objected to. Paradoxically, the approach that was supposed to 'liberate' residents from traditional participation regimes has resulted in support measures that feel like a straitjacket for their beneficiaries.

The third paradox relates to the supposed independent and self-sufficient nature of CEs, which is one of defining principles set by LSA. However, residents themselves claim that they lack the knowledge and skills to properly establish and manage CEs, need intensive support and therefore cannot be independent, at least in the starting up phase. Paradoxically, this stance is in line with earlier research (OECD, 2003; Greene et al., 2007; Williams and Williams, 2012), but opposed to the current active citizenship 
and do-it-yourself policy discourse which claims that neighbourhood residents are equipped to and should self-organise in entrepreneurial terms (Wells, 2011; Bailey and Pill, 2015; Uitermark, 2015).

A fourth and related paradox is that active residents have ascribed to the LSA the type of role that LSA had distanced itself from, i.e. professionals with expertise who provide direct answers when problems occur. A case in point is the mismatch between the procedure of business plan approval by the external evaluation committee, and the counselling offered, evidenced by a lacking consensus between the committee and LSA regarding the criteria for the business plan. This has resulted in delayed and improper advice and, consequently, frustration among many CE initiators. Even though nascent CEs were supposed to develop themselves, all eyes were usually turned to the LSA to provide answers to the 'wicked questions'. These findings give reason to be very critical towards overly positive views on residents' ability to self-organise in deprived communities (see also Kisby, 2010, Lawless, 2011), and to acknowledge that the help of supporting but not patronizing professionals remains necessary. This is easier said than done in light of contradictory support needs. On the one hand, respondents have claimed that several 'entrance criteria' (e.g. the business plan formats) have been unclear, but on the other hand, they argue that supporting professionals should not prescribe too much beforehand to allow for experimentation. This seems a very difficult balance to strike for support counsellors. The general lessons learnt here are 1) that support professionals have to balance carefully between providing guidelines and giving free rein to residents, and 2) that the commonly praised method of experimentation requires recognition of the fact that this does not only implies a full learning process for active citizens, but also a steep learning curve for supporting organisations.

\section{References}

Bacq, S., and Janssen, F. 2011. "The multiple faces of social entrepreneurship: A review of definitional issues based on geographical and thematic criteria." Entrepreneurship \& Regional Development 23 (5-6): 373-403.

Bailey, N. 2012. "The role, organisation and contribution of community enterprise to urban regeneration policy in the UK." Progress in Planning 77 (1): 1-35.

Bailey, N. and Pill, M. 2015. "Can the state empower communities through localism? An evaluation of recent approaches to neighbourhood governance in England." Environment and Planning C: Government and Policy 33 (2): 289-304.

Baumol, W. J., Litan, R. E. and Schramm, C. J. 2007. Good capitalism, bad capitalism, and the economics of growth and prosperity, New Haven: Yale University Press.

Bjørnå, H. and Aarsæther, N. 2010, "Local government strategies and entrepreneurship." International Journal of Innovation and Regional Development 2 (1): 50-65.

Blackburn, R. and Ram, M. 2006. "Fix or fixation? The contributions and limitations of entrepreneurship and small firms to combating social exclusion." Entrepreneurship \& Regional Development 18 (1): 73-89.

Carpenter, J. 2013. "Social Enterprise and Urban Regeneration: a Model for the Future?" Calitatea Veţi= Quality of Life Journal 14 (2): 137-156.

Crang, M. 2002, "Qualitative methods: the new orthodoxy?" Progress in Human Geography 26: 647-655.

Dana, L. P. 1995. "Entrepreneurship in a remote sub-Arctic community." Entrepreneurship Theory and Practice 20: 57-72. 
Dana, L. P. and Dana, T. E. 2005. "Expanding the scope of methodologies used in entrepreneurship research." International Journal of Entrepreneurship and Small Business 2 (1): 79-88.

Dart, R. 2004. "The legitimacy of social enterprise." Nonprofit management and leadership 14 (4): 411-424.

Fortunato, M. W. and Alter, T. 2015. "Community entrepreneurship development: an introduction." Community Development 46 (5): 444-455.

Guba, E. G. and Lincoln, Y. S. 1982. "Epistemological and methodological bases of naturalistic inquiry." Educational Technology Research and Development 30 (4): 233-252.

Greene, F., Mole, K. and Storey, D. 2007. Three Decades of Enterprise Culture? Entrepreneurship, Economic Regeneration and Public Policy. London: Palgrave Macmillan.

Healy, P. 2015. "Civil society enterprise and local development." Planning Theory and Practice 16 (1): 11-27.

Henry, C. and Foss, L. 2015. "Case sensitive? A review of the literature on the use of case method in entrepreneurship research." International Journal of Entrepreneurial Behavior and Research 21 (3): 389-409.

Honig, B. and Dana, L. 2008. "Communities of disentrepreneurship: A comparative cross-national examination of entrepreneurial demise." Journal of Enterprising Communities: People and Places in the Global Economy 2 (1): 5-20.

Hopp, C. and Stephan, U. 2012. "The influence of socio-cultural environments on the performance of nascent entrepreneurs: Community culture, motivation, selfefficacy and start-up success." Entrepreneurship \& Regional Development 24 (9-10): 917-945.

Kisby, B. 2010. "The Big Society: power to the people?” The Political Quarterly 81 (4): 484-491.

Kleinhans, R., Doff, W., Romein, A. and Ham, M. van 2015. Project Kennisontwikkeling Experiment Bewonersbedrijven - Eindrapportage [Project Knowledge Experiment Community Enterprises - Final Report]. Delft: Delft University of Technology, Faculty of Architecture and the Built Environment.

Lawless, P. 2011. "Big Society and community: lessons from the 1998-2011 New Deal for Communities Programme in England." People, Place \& Policy Online 5 (2): 55-64.

LSA 2011. Projectplan Experiment BewonersBedrijven Nederland [Project Plan Experiment Community Enterprises]. Utrecht: Landelijk Samenwerkingsverband Aandachtswijken.

LSA 2015. Tussenrapportage BewonersBedrijven [Interim Report Community Enterprises]. Utrecht: Landelijk Samenwerkingsverband Actieve Bewoners.

Lundqvist, M. A. and Middleton, K. L. 2010. "Promises of societal entrepreneurship: Sweden and beyond." Journal of Enterprising Communities: People and Places in the Global Economy 4 (1): 24-36.

Lyons, T. S. 2015. "Entrepreneurship and community development: what matters and why?" Community Development 46 (5): 456-460.

Lyons, T. S., Alter, T. R., Audretsch, D. and Augustine, D. 2012. "Entrepreneurship and community: The next frontier of entrepreneurship inquiry." Entrepreneurship Research Journal 2 (1): 1-23.

Mason, C., Reuschke, D., Syrett, S. and Ham, M. van, Eds. 2015. Entrepreneurship in cities: neighbourhoods, households and homes. Cheltenham: Edward Elgar. 
McKeever, E., Anderson, A. and Jack, S. 2014. "Entrepreneurship and mutuality: social capital in processes and practices." Entrepreneurship \& Regional Development 26 (5-6): 453-477.

Miles, M. and Huberman, A. 1994. Qualitative data analysis: An expanded sourcebook. Thousand Oaks: Sage Publications.

Newman, J. and Tonkens, E. 2011. Participation, responsibility and choice: summoning the active citizen in western European welfare states. Amsterdam: Amsterdam University Press.

OECD 2003. Entrepreneurship and local economic development: programme and policy recommendations. Paris: Organisation for Economic Co-operation Development Publishing.

Painter, J., Orton, A., Macleod, G., Dominelli, L. and Pandre, R. 2011. Connecting localism and community empowerment. Durham: Durham University, Department of Geography and School of Applied Social Sciences.

Pearce, J.2003. Social enterprise in anytown. London: Calouste Gulbenkian Foundation, London.

Peredo, A. M. and Chrisman, J. J. 2006. "Toward a theory of community-based enterprise." Academy of Management Review 31 (2): 309-328.

Pierre, A., Von Friedrichs, Y. and Wincent, J. 2014. "Entrepreneurship in Society: A Review and Definition of Community-Based Entrepreneurship Research". In: Lundström, A., Zhou, C., Von Friedrichs, Y. and Sundin, E, Eds. Social Entrepreneurship. Leveraging Economic, Political, and Cultural Dimensions. Switzerland, Springer International Publishing.

Ratten, V. and Welpe, I. 2011. "Guest Editorial: Community-based, social and societal entrepreneurship." Entrepreneurship \& Regional Development 23 (5-6): 283286.

Selsky, J. W. and Smith, A. E. 1994. "Community entrepreneurship: A framework for social change leadership." The Leadership Quarterly 5 (3-4): 277-296.

Shane, S. 2009. "Why encouraging more people to become entrepreneurs is bad public policy." Small Business Economics 33 (2): 141-149.

Smith, R. 2012. "Developing and animating enterprising individuals and communities: A case study from rural Aberdeenshire, Scotland." Journal of Enterprising Communities: People and Places in the Global Economy 6 (1): 57-83.

Somerville, P. and McElwee, G. 2011. "Situating community enterprise: A theoretical exploration." Entrepreneurship \& Regional Development 23 (5-6): 317-330.

Sundin, E. 2011. "Entrepreneurship and social and community care." Journal of Enterprising Communities: People and Places in the Global Economy 5 (3): 212-222.

Teasdale, S. 2010. "How Can Social Enterprise Address Disadvantage? Evidence from an Inner City Community." Journal of Nonprofit and Public Sector Marketing 22 (2): 89-107.

Tracey, P., Phillips, N. and Haugh, H. 2005. "Beyond philanthropy: community enterprise as a basis for corporate citizenship." Journal of Business Ethics 58 (4): $327-344$.

Uitermark, J. 2015. "Longing for Wikitopia: The study and politics of selforganisation." Urban Studies 52 (1): 2301-2312.

Van Meerkerk, I., Booonstra, B. and Edelenbos, J. 2013. "Self-Organization in Urban Regeneration: A Two-Case Comparative Research." European Planning Studies 21 (1): 1630-1652. 
Varady, D., Kleinhans, R. and Ham, M. van 2015. "The potential of community entrepreneurship for neighbourhood revitalization in the United Kingdom and the United States". Journal of Enterprising Communities: People and Places in the Global Economy 9 (3): 253-276.

Wells, P. 2011. "Prospects for a Big Society? Special Issue of People Special Issue of People Place and Policy." People, Place and Policy Online 5 (2): 50-54.

Welter, F., Trettin, L. and Neumann, U. 2008. "Fostering entrepreneurship in distressed urban neighbourhoods." International Entrepreneurship and Management Journal 4 (2): 109-128.

Williams, C. C. 2007. "Socio-spatial variations in the nature of entrepreneurship." Journal of Enterprising Communities: People and Places in the Global Economy 1 (1): 27-37.

Williams, N. and Huggins, R. 2013. "Supporting entrepreneurship in deprived communities: a vision too far?" Journal of Small Business and Enterprise Development 20 (1): 165-180.

Williams, N. and Williams, C. C. 2012. "Evaluating the socio-spatial contingency of entrepreneurial motivations: A case study of English deprived urban neighbourhoods." Entrepreneurship \& Regional Development 24 (7-8): 661684.

Yin, R. 2012. Applications of case study research, $3^{\text {rd }}$ edition. Thousand Oaks: Sage Publications.

Zimmer, A. and Bräuer, S. 2014. The Development of Social Entrepreneurs in Germany - Literature Review, EU KP7-EFESEIIS Project. , Münster: Westfälische Wilhelms University. 